\title{
Normas anormais
}

\author{
Ivanildo Hespanhol*
}

DOI: http://dx.doi.org/10.4322/dae.2014.001

\section{Introdução}

Recentemente um importante jornal paulistano publicou a seguinte notícia "Estado de São Paulo é $o 1^{\circ}$ do mundo a ter padrão mais rígido de qualidade do ar". (O OESP, 2011). Embora possa ter sido alvissareira para leigos, esta notícia trouxe dúvidas a muitos ambientalistas. Seria a norma mais restrita do mundo adequada para avaliar um perfil de poluição atmosférica, que, certamente, não é o melhor do mundo? A resposta veio através de outra notícia publicada no mesmo jornal (OESP, 2011a): "Ar foi ruim 3 vezes em 2 anos; na nova regra seriam 1.855". Diversas outras notícias foram publicadas em sequência, estre as quais: "Poluição por ozônio é a pior da década - em 98 dias do ano passado, a taxa de poluentes na Grande São Paulo ficou acima do aceitável" (OESP,2013); "Após 23 anos Estado de SP adota padrão mais rígido de qualidade do ar" (OESP, 2013a). Neste artigo é salientado que "no ano passado, 98 dias tiveram qualidade do ar inadequada por ozônio na capital". Em parte do texto uma afirmação bombástica mostra a irrealidade da norma proposta : "o padrão é mais rígido do que o previsto para ser adotado pela União Europeia até 2015".

Serão esses meros valores numéricos atribuídos a padrões de qualidade do ar, os mais restritivos do mundo, capazes de proteger a nossa população de problemas respiratórios, episódios de inversão térmica e redução da visibilidade e muitos outros provocados pelo nível atual de poluição atmosférica?

O objetivo de normas é o de atribuir valores numéricos realísticos a variáveis localmente significativas, com a finalidade de dar suporte a sistemas operacionais de comando e controle, associados à realidade e características de cada região ou país onde o controle é exercido. Normas não podem ser confundidas com propostas ufanistas, com a falsa pretensão de sermos os mais rígidos do mundo em termos de proteção ambiental. Não podem, também, ser promulgadas na condição de instrumen- tos políticos, impondo a falsa promessa de que os nossos órgãos controladores efetuam, com esmero e extrema rigidez, a proteção dos grupos de risco expostos à poluição ambiental.

Há que considerar, ainda, que a qualidade do ar sofrerá, no Brasil, uma significativa deterioração nos próximos anos, em face da eminente implantação de grande número de usinas termoelétricas a carvão, em função do Plano Decenal de Expansão de Energia. Devido à forte pressão de ambientalistas, proibindo a formação de reservatórios de acumulação para regularização de vazões anuais, ocorrerá uma significativa redução de geração da energia a ser produzida por usinas hidroelétricas que vêm sendo construídas no Brasil. A operação a fio d'agua, exigido para as usinas hidroelétricas licenciadas (Jirau, Belo Monte e Teles Pires) além de ser absolutamente antieconômica em termos de potência gerada, não permitirá o atendimento da demanda nacional prevista para a próxima década, daí a necessidade de complementar o sistema hidroelétrico com usinas térmicas a carvão.

\section{Diretrizes e normas}

Uma das diversas funções da OMS no atendimento de seus objetivos é a de ... "propor ... regulamentos e efetuar recomendações relativas a temas internacionais de saúde... (WHO, 1990).

Como parte importante dessas funções a OMS estabelece, através de dois estágios distintos, diretrizes para a qualidade da água potável, para reúso de esgotos, para controle da poluição atmosférica, etc. O primeiro estágio, designado como "Avaliação de Riscos", inclui: i) a identificação, em nível mundial, de contaminantes potencialmente perigosos (microbiológicos, químicos e radiológicos); (ii) avaliação quantitativa da relação doses-efeitos sobre seres humanos, e; (iii) avaliação dos níveis potenciais de exposição que podem ocorrer sobre seres humanos. Esta primeira fase atribui valores diretrizes aos contaminantes considerados relevantes e é dirigida 
fundamentalmente à proteção da saúde pública. Essas diretrizes têm características unicamente "recomendatórias" e são baseadas na filosofia de risco/ benefício. As diretrizes assim formuladas proporcionam aos países membros da OMS, elementos para o estabelecimento de padrões nacionais de temas que envolvem a saúde pública dos respectivos grupos de risco. A adoção indiscriminada e direta das diretrizes da OMS não é, portanto, a maneira adequada de estabelecer padrões de qualidade em qualquer país.

A segunda etapa, denominada "Gestão do Risco", é desenvolvida em nível nacional e com eventual suporte técnico da OMS, por países interessados em desenvolver seus padrões e códigos de prática. Consiste na interpretação das diretrizes, levando em conta as condições e características técnicas econômicas e de sensibilidade das sociedades locais. Esta etapa formula padrões REALISTAS, compatíveis com os interesses e as tendências nacionais. A consideração sobre "gestão de riscos", implica o fato de que diretrizes não são produzidas com o objetivo de serem aplicadas de maneira direta e absoluta, em todos os países. Elas visam estabelecer um determinado nível de saúde pública, associada a riscos preestabelecidos, fornecendo assim uma referência comum para o estabelecimento de padrões nacionais ou regionais. Possuem uma característica consultiva baseada no estado-da-arte da pesquisa científica e de estudos epidemiológicos, e não devem ser confundidas com padrões legais.

Padrões, por outro lado, são instrumentos legais, promulgados em cada país, através da adaptação de diretrizes às prioridades nacionais e com base em suas condições ambientais, econômicas, culturais, sociais, tecnológicas e em seus condicionantes políticos e institucionais. Padrões devem ser estabelecidos, promulgados e aplicados por autoridades nacionais competentes, através da adoção de um critério de risco/ benefício. A qualquer época podem ser substituídos ou alterados, sempre que novas evidências científicas ou inovações tecnológicas se tornem disponíveis, ou em obediência à evolução de interesses e tendências nacionais.

A diretriz da Organização Mundial da Saúde para água potável (WHO,1990a), por exemplo, especifica, claramente, que "No desenvolvimento de padrões nacionais para água potável, baseado nessas diretrizes, é necessário levar em conta uma multiplicidade de fatores e aspectos geográficos, socioeconômicos, dietários e industriais que reflitam as condições locais. Essas considerações podem levar ao desenvolvimento de padrões nacionais que diferem substancialmente das variáveis e valores numéricos contidos nessas diretrizes".

Por outro lado, a evolução de diretrizes e normas relativas a temas de saúde pública não é controlada unicamente por estudos e pesquisas toxicológicas e epidemiológicas. Características sócio-culturais, práticas de higiene, percepção e sensibilidade públicas, desenvolvimento tecnológico e condições econômico - financeiras são tão importantes quanto evidências científicas no estabelecimento de normas para a proteção da saúde pública de usuários de sistemas por elas controlados. (Hespanhol \& Prost, 1994). O objetivo básico de produzir regulamentos é o de estabelecer limites relativos a práticas específicas (tais como abastecimento ou reúso de água) que minimizem os efeitos detrimentais sem afetar os benefícios correspondentes. Esses limites não possuem valor absoluto nem podem ser considerados como permanentes. Variam em função do desenvolvimento científico e tecnológico e de condições econômicas, assim como em função de tendências de aceitação ou rejeição de práticas e posturas que afetam os valores culturais de uma sociedade.

\section{As normas para aplicação de biossólidos}

Existem dois critérios para estabelecer normas para disposição de biossólidos ou esgotos no solo. Um deles é "prevenir a acumulação de poluentes nos solos", através de variáveis significativas e respectivos valores numéricos impostos a biossólidos ou a esgotos a serem depositados. Este critério assume que a introdução de poluentes no solo é compensada por uma remoção correspondente, através de escoamento superficial, lixiviação, evaporação e absorção pelas plantas. Este critério tem a vantagem de não necessitar de dados relativos a transporte e degradação de poluentes, cenários de exposição e relações doses-respostas. Os valores numéricos a serem estabelecidos para os parâmetros regulamentados podem ser calculados através de simples balanços de massas, podendo ser aplicados universalmente. Por outro lado, leva a valores numéricos extremamente restritivos, que exigem sistemas avançados de tratamento, ou a taxas de aplicação muito restritas.

O segundo critério é o que visa "maximizar a capacidade do solo em assimilar e atenuar o efeito de poluentes”. É necessário, entretanto, que a aplicação seja adequadamente controlada, evitando que a acumulação de poluentes atinja níveis que afetem 
a saúde pública dos consumidores dos produtos agrícolas produzidos. Nesse sentido, as concentrações de poluentes no solo não poderão ultrapassar os níveis máximos toleráveis a serem estabelecidos para cada um deles (Chang, Page, Asano, 1998 e Hespanhol,2002;)

Na aplicação de esgotos ou de biossólidos a solos agrícolas, são identificadas diversas rotas de exposição, através das quais os poluentes podem atingir seres humanos. Conhecendo esses cenários de exposição, as taxas de transferência de poluentes e as quantidades de poluentes transferidos em cada fase da cadeia de transmissão são determinadas as concentrações máximas permitidas no solo. Torna-se necessário, entretanto, que todos os poluentes importantes, contidos nos efluentes ou biossólidos aplicados, sejam analisados através dessas rotas de exposição e adequadamente regulamentados. Esse critério leva a valores diretrizes aceitáveis, não apenas do ponto de vista ambiental e de saúde pública, mas também no que concerne aos custos de tratamento envolvidos, permitindo a sua aplicação em países que não disponham de recursos financeiros para implementar sistemas avançados de tratamento. Dentro desse critério deverão ser estabelecidos os limites máximos de concentrações de poluentes no solo agrícola (em $\mathrm{mg} / \mathrm{kg}$ ou $\mu \mathrm{g} / \mathrm{kg}$ de solo seco). Uma vez atingido esse limiar a aplicação de esgotos ou lodos no solo não será mais permitida, tomando-se como referência a variável que se apresenta em concentração limite.

Esse segundo critério é, portanto, mais adequado do que estabelecer valores numéricos de poluentes significativos no esgoto ou no biossólido. A determinação de valores numéricos máximos de poluentes contidos em solos agrícolas é efetuada de acordo com as seguintes fases: (i) identificação de poluentes tóxicos potenciais de ocorrência significativa para serem regulamentados em uma determinada região ou país, utilizando dados toxicológicos e epidemiológicos; (ii) definição da Dose-Resposta, determinando as Doses Diárias Aceitáveis - DDA, expressas em miligramas por dia por $\mathrm{kg}$ de peso corporal (mg/dia/kgPC) associadas a todos os poluentes tóxicos considerados relevantes para regulamentação. (iii) Análise de Exposição, estabelecendo as rotas de exposição mais prováveis, através das quais os grupos de risco possam vir a se expor à ação dos poluentes potenciais, advindos de biossólidos ou efluentes aplicados em áreas agrícolas. Em seguida, são determinados os coeficientes de transferência de poluentes (solo/planta) em cada interface, das rotas de transmissão, consideradas mais relevantes. Entre as 14 rotas de exposição, cada uma com cenários completos e bem definidos, é considerada como a mais significativa a que contém os seguintes integrantes da cadeia de transporte: biossólido (ou esgoto)-solo-planta-humano, assumindo que a ingestão de poluentes, através do consumo de alimentos irrigados com esgotos ou fertilizados com biossólidos, se constitui na rota ambiental mais crítica em termos de efeitos sobre consumidores de culturas irrigadas com esgotos ou fertilizadas com biossólidos ou efluentes.

Considerando-se esta rota de transmissão como a mais crítica, deve ser estabelecido um cenário de exposição com base em um padrão de consumo alimentar, para determinar, em associação com as DDAs correspondentes aos poluentes a serem regulamentados, as concentrações máximas permitidas desses poluentes nos solos irrigados ou fertilizados com efluentes ou biossólidos.

$\mathrm{O}$ padrão de consumo alimentar baseia-se nos dados de consumo médio de alimentos relacionados pelo FAO Food Balances Sheet (Galal-Gorchev, 1991) que estabelece que $76 \%$ do consumo diário corresponde a grãos e cereais, vegetais, raízes e tubérculos e frutas, conforme resumido no Quadro 1.

Quadro 1- Dieta Global Estabelecida pela United Nations Food and Agriculture

Organization-FAO (Galal-Gorchev, 1991)

\begin{tabular}{c|c|c} 
ALIMENTO & $\mathrm{C}_{\mathrm{a}}$-CONSUMO $(\mathrm{kg}$ bruto / dia) & $\mathrm{S}_{\mathrm{B}}$ (kg seco / kg bruto) \\
\hline Grãos e Cereais & 0,405 & 0,90 \\
\hline Vegetais & 0,212 & 0,05 \\
\hline Raízes e Tubérculos & 0,288 & 0,20 \\
\hline Frutas & 0,225 & 0,05
\end{tabular}


O potencial de transferência de poluentes através de outros grupos alimentares, tais como laticínios e produtos animais, óleos e gorduras, açúcares, mel, etc. é relativamente muito pequeno, não sendo, portanto, considerados no padrão de consumo alimentar.

Para determinar os níveis máximos de contaminação que um solo pode suportar, deve-se partir do nível máximo aceitável pelos consumidores humanos (DDA) e percorrer, retroativamente, através da adoção de coeficientes adequados, a rota de transmissão escolhida.

Estabelecendo os valores:

DDA= Dose Diária Aceitável de cada poluente a ser considerado importante para ser regulamentado (mg/dia/kg de peso corporal).

$\mathrm{PC}=$ Peso corporal de um adulto, estimado em $60 \mathrm{~kg}$,

$\mathrm{P}_{\mathrm{e}}=$ Fração da DDA que é assimilada através dos alimentos considerados na dieta global.

$\mathrm{C}_{\mathrm{A}}=$ Consumo de alimentos $(\mathrm{kg} / \mathrm{dia})$ conforme indicado no Quadro 1.

$\mathrm{F}_{\mathrm{A}}=$ Fração da dieta global (Quadro 1) que é oriunda de campos irrigados ou fertilizados com esgotos ou lodos.

$\mathrm{K}_{\mathrm{S}}=$ Fator de transferência de poluentes do solo para plantas (alimentos) expresso em mg de poluente/kg de alimento por mg de poluente/kg de solo. Esse fator estabelece as concentrações dos diversos poluentes que podem ser encontrados em plantas (em mg/kg) em função das concentrações correspondentes que ocorrem no solo onde se desenvolvem (também em $\mathrm{mg} / \mathrm{kg}$ ).

Os fatores de transferência de compostos inorgânicos são obtidos de estudos geoquímicos efetuados em nível global (Kabata-Pendias e Pendias, 1984). Os associados a grãos e cereais, raízes e tubérculos e frutas são derivados de valores médios de dados tabulados de fontes diversas em nível mundial (USEPA, 1992).

$\mathrm{S}_{\mathrm{B}}=$ Relação Alimento Peso Seco/Alimento Peso Bruto (kg/kg), conforme indicado no Quadro 1, $\mathrm{i}=$ Índice, representando grãos e cereais, vegetais, raízes e tubérculos, e frutas,

Obtém-se $\mathrm{C}_{\mathrm{S}}$ que é a Concentração máxima de poluentes permitida no solo (mg de poluente / kg de solo seco) através da equação1.

Assumindo valores numéricos representativos às variáveis acima relacionadas e os valores de $C_{A}$ e $S_{B}$ indicados no Quadro 1, os valores de DDA correspondentes a cada variável a ser regulamentada e os correspondentes valores de $\mathrm{K}_{\mathrm{s}}$ estabelecidos em países em desenvolvimento (Chang, Page, Asano, 1995 e Kabata-Pendias et al.1984), obtêm-se os valores numéricos das concentrações máximas de poluentes prioritários, permitidos em solos agrícolas, em mg por quilograma de solo seco, $\mathrm{C}_{\mathrm{S}}$ mostrados no Quadro 2.

Esta metodologia pode ser vista em seus detalhes em Chang, Page, Asano, 1995, Chang, Page, Asano e Hespanhol, 1998 e em Hespanhol, 2002.

Essa avaliação é muito mais objetiva e representativa do que apenas controlar as concentrações em efluentes ou biossólidos. O importante é verificar que quando essas concentrações forem atingidas, o solo em consideração não mais poderá receber efluentes ou biossólidos.

Evidentemente, tanto as variáveis relacionadas acima assim como seus respectivos valores numéricos não poderão ser adotadas indiscriminadamente em normas brasileiras. É necessário verificar: (i) se essas variáveis ocorrem no Brasil ou se outras não listadas devem ser consideradas; (ii) se a Dieta da FAO representa as condições alimentares brasileiras; (iii) se os fatores de transferência de poluentes do solo para plantas (alimentos), expresso em mg de poluente/kg de alimento em relação a mg de poluente/kg de solos, são representativos de nossos solos agrícolas, etc.

Entretanto, no Brasil, a tendência é de, indiscriminadamente, adotar, para temas associados à saúde pública de grupos de riscos, variáveis e respectivos valores numéricos de normas alienígenas ou, sem adaptação, das diretrizes da OMS.

$$
C s=\frac{\left[D D A\left(\frac{m g}{\text { dia. } \mathrm{kg} \cdot \mathrm{PC}}\right) \cdot \mathrm{PC}(\mathrm{kg}) \cdot P_{e}\right]}{\sum_{i=1}^{i=4}\left[C_{A_{i}}\left(\frac{\mathrm{kg}}{\text { dia }}\right) \cdot F_{A_{i}} K_{S_{i}} \cdot\left(\frac{\mathrm{mg} \text { poluente } / \mathrm{kg} \text { alimento }}{m g \text { poluente } / \mathrm{kg} \mathrm{solo}}\right) S_{B_{i}}\right.}
$$


Quadro 2- Valores Numéricos das Concentrações Máximas de Poluentes Permitidos em Solos Agrícolas Irrigados com Esgotos ou Fertilizados com Biossólidos, CS em mg de poluente/kg de solo seco (Chang, Page e Asano,1995)

\begin{tabular}{|c|c|c|c|}
\hline POLUENTE & $\mathrm{C}_{\mathrm{s}}(\mathrm{mg} / \mathrm{kg}$ solo seco) & POLUENTE & $\mathrm{C}_{\mathrm{s}}(\mathrm{mg} / \mathrm{kg}$ solo seco) \\
\hline \multicolumn{2}{|c|}{ INORGÂNICOS: } & \multicolumn{2}{|c|}{ ORGÂNICOS: } \\
\hline Arsênico & 9 & Aldrin & 0,2 \\
\hline Bário & 2900 & Benzeno & 0.03 \\
\hline Berílio & 20 & Benzo(a)pireno & 3 \\
\hline Cádmio & 7 & Clordano & 0,3 \\
\hline Cromo & 3200 & Clorobenzeno & ND \\
\hline Flúor & 2600 & Clorofórmio & 2 \\
\hline Chumbo & 150 & Diclorofenóis & ND \\
\hline Mercúrio & 5 & $2,4-D$ & 10 \\
\hline Níquel & 850 & DDT & ND \\
\hline Selênio & 140 & Dieldrin & 0,03 \\
\hline \multirow[t]{14}{*}{ Prata } & 3 & Heptacloro & 1 \\
\hline & & Hexaclorobenzeno & 40 \\
\hline & & Hexacloroetano & 2 \\
\hline & & Pireno & 480 \\
\hline & & Lindano & 0,6 \\
\hline & & Metoxicloro & 20 \\
\hline & & Pentaclorofenol & 320 \\
\hline & & $\begin{array}{l}\text { Bifenilas Poli- } \\
\text { cloradas }\end{array}$ & 30 \\
\hline & & Tetracloroetano & 4 \\
\hline & & Tetracloroetileno & 250 \\
\hline & & Tolueno & 50 \\
\hline & & Toxafeno & 9 \\
\hline & & $2,4,5-T$ & ND \\
\hline & & $2,3,7,8 \mathrm{TCDD}$ & 30 \\
\hline
\end{tabular}

$N D=$ Valores numéricos não detectados devido à insuficiência de dados para computação

As normas disponíveis para regulamentar a disposição de biossólidos em solos agrícolas adotadas no Brasil são apresentadas no Quadro 3, incluindo as da EPA 40 Part 503, as do CONAMA 375/2006 e as da CETESB P4230/1999.

O Quadro 3 mostra que as variáveis e respectivos valores numéricos adotados na P4230/1999 constituem-se em uma simples e direta cópia daquelas estabelecidas na EPA 40 Part 503, sem considerar se essas variáveis são representativas das condições brasileiras e sem analisar, como mostrado no item acima, se esses valores numéricos implicariam problemas de saúde pública através de ingestão de alimentos produzidos em áreas agrícolas fertilizados por biossólidos. Nota-se que a cópia é efetuada sem a menor consideração das condições vigentes no Brasil. Ovos viáveis de helmintos, por exemplo, não são regulamentados porque não há ocorrência deste tipo de patogênico nos Estados Unidos. Como a cópia é efetuada sem qualquer análise ou adaptação, ovos de helmintos não foram, também, considerados como relevantes no Brasil. Por outro lado, o CONAMA 375/2006 é tão restritivo que não seria necessária a preocupação em estabelecer variáveis 
Quadro 3- Variáveis e concentrações máximas permitidas em biossólidos para aplicação agrícola (EPA, CONAMA e CETESB)

\begin{tabular}{|c|c|c|c|}
\hline \multirow{3}{*}{ Variável } & \multicolumn{3}{|c|}{ Concentração máxima permitida no biossólido } \\
\hline & EPA 40 Part 503 & CONAMA 375/2006 & CETESB P4230/1999 \\
\hline & \multicolumn{3}{|c|}{ Substâncias Inorgânicas (mg/kg BS) } \\
\hline Arsênio & 75 & 41 & 75 \\
\hline Bário & - & 1300 & - \\
\hline Cádmio & 85 & 39 & 85 \\
\hline Cromo & 3000 & 1000 & - \\
\hline Cobre & 4300 & 1500 & 4300 \\
\hline Chumbo & 840 & 300 & 840 \\
\hline Mercúrio & 57 & 17 & 57 \\
\hline Molibdênio & 75 & 50 & 75 \\
\hline Níquel & 420 & 420 & 420 \\
\hline Selênio & 100 & 100 & 100 \\
\hline Zinco & 7500 & 2800 & 7500 \\
\hline \multicolumn{4}{|c|}{ Indicadores Bacteriológicos e agentes patogênicos (Classe A) } \\
\hline Coliformes Termotolerantes & $<1000 \mathrm{NMP} / \mathrm{gMS}$ & $<1000 \mathrm{NMP} / \mathrm{gST}$ & $<1000 \mathrm{NMP} / \mathrm{gST}$ \\
\hline Ovos viáveis Helmintos & - & $<0,25$ ovos/gST & - \\
\hline Salmonella & $<3 \mathrm{NMP} / 4 \mathrm{gMS}$ & ausência em 10 gST & $<3 \mathrm{NMP} / 4 \mathrm{gMS}$ \\
\hline Vírus & $<1$ UFP ou UFF/4 gST & $<0,25$ UFP ou UFF/ gST & - \\
\hline
\end{tabular}

e valores numéricos, pois bastaria especificar que "fica expressamente proibida a aplicação de efluentes ou biossólidos em solos agrícolas brasileiros", o que seria uma grande perda econômica e ambiental, pois anularia por completo a possibilidade de utilizar um recurso extremamente importante como condicionador do solo.

\section{As normas para água potável}

As considerações efetuadas no item 2. Diretrizes e Normas, isto é, a adoção dos dois procedimentos distintos, ou seja, a "Avaliação de Riscos" e a "Gestão dos Riscos" é também válida para estabelecer diretrizes e normas para água potável.

A recém revisada Portaria MS 2.914 de 12.12.2011, (que "dispõe sobre os procedimentos do controle e da vigilância da qualidade da água para consumo humano e seu padrão de potabilidade") e suas edições anteriores (56 BSB/1977, GM 36/1979, GM 519/2004) não elaborou a fase de Gestão de Riscos uma vez que adotou, sem a necessária adaptação, praticamente todas as variáveis propostas pelas diretrizes da OMS (WHO, 2011). Os valores numéricos adotados para essas variá- veis são, também, os mesmos propostos pela OMS. Como exemplo, poderão ser citados : Arsênio (0,01 $\mathrm{mg} / \mathrm{L})$, Bário (0,7 mg/L), Chumbo $(0,01 \mathrm{mg} / \mathrm{L})$, Fluoreto $(1,5 \mathrm{mg} / \mathrm{L})$, Níquel $(0,07 \mathrm{mg} / \mathrm{L})$, Nitrato e Nitrito ( os valores diretrizes da OMS foram arredondados, de $11 \mathrm{mg} / \mathrm{L} \mathrm{e} \mathrm{0,9} \mathrm{mg/L} \mathrm{respectivamente,}$ para $10 \mathrm{mg} / \mathrm{L}$ e $1 \mathrm{mg} / \mathrm{L}$ respectivamente), Urânio (0,03 mg/L), Acrilamida (0,5 $\mu \mathrm{g} / \mathrm{L})$, Benzo[a]pireno (0,7 $\mu \mathrm{g} / \mathrm{L}), 1,2$ dicloroeteno (50 $\mu \mathrm{g} / \mathrm{L})$, Diclorometano $(20 \mu \mathrm{g} / \mathrm{L})$, Estireno $(20 \mu \mathrm{g} / \mathrm{L})$, Pentaclorofenol $(9 \mu \mathrm{g} / \mathrm{L})$, Tetracloreto de carbono $(4 \mu \mathrm{g} / \mathrm{L})$, Tetracloroeteno $(40 \mu \mathrm{g} / \mathrm{L})$, Alaclor $(20 \mu \mathrm{g} / \mathrm{L}), \mathrm{Al}$ dicarbe+Aldicarbesulfona+Aldicarbesulfóxido $\quad(10$ $\mu \mathrm{g} / \mathrm{L})$, Aldrin + Dieldrin $(0,03 \mu \mathrm{g} / \mathrm{L})$, Carbofurano (7 $\mu \mathrm{g} / \mathrm{L})$, Clordano $(0,2 \mu \mathrm{g} / \mathrm{L})$, DDT+DDD+DDE (1 $\mu \mathrm{g} / \mathrm{L})$, Lindano $(2 \mu \mathrm{g} / \mathrm{L})$, Bromato $(0,01 \mathrm{mg} / \mathrm{L})$, Sulfato $(250 \mathrm{mg} / \mathrm{L})$, Microcistinas $(1,0 \mu \mathrm{g} / \mathrm{L})$.

Valores numéricos de algumas outras variáveis parecem ter sido adotados ou adaptados da legislação americana (EPA, 2011). Alguns exemplos dessas são: Benzeno (5 $\mu \mathrm{g} / \mathrm{L}$ ), enquanto o valor diretriz proposto pela OMS é de $10 \mu \mathrm{g} / \mathrm{L}$, Cloreto de Vinila (2 $\mu \mathrm{g} / \mathrm{L})$, Antimônio (0,006 mg/l da EPA arredondado para 0,005 mg/L na Portaria 2914). 
As normas promulgadas no Brasil são geralmente baseadas ou copiadas de normas estrangeiras, ou adotadas sem a devida adaptação das diretrizes correspondentes estabelecidas pela OMS, podendo vir a ser, de um lado, extremamente restritivas e, portanto, não dar condições para a sua devida aplicação, ou podendo, por outro, não exercer a proteção que delas se espera, uma vez que não são representativas de nossas condições de saúde pública.

Esta prática leva a questões fundamentais, entre as quais: serão as variáveis regulamentadas dessa maneira e seus respectivos valores numéricos representativos das condições ambientais e de saúde pública vigentes no Brasil? Com o critério de adotar variáveis diretamente de diretrizes internacionais ou de normas alienígenas não ocorre a possibilidade de que estejamos regulamentando variáveis que não sejam significativas dentro de nossas condições e, por outro lado, não é possível que estejamos deixando de regulamentar variáveis que, por não ser consideradas importantes, não são regulamentadas nos países de origem das normas, mas que implicariam problemas de saúde pública se não fossem regulamentadas no Brasil? E quanto aos valores numéricos adotados para essas variáveis? Quando se considera as normas de qualidade de água potável, serão as respectivas doses-respostas e seus efeitos sobre os grupos de risco os mesmos para as nossas condições médias de saúde pública, quando comparadas com as adotadas nas diretrizes internacionais e com as dos países que originaram as normas nas quais nos inspiramos?

Além dessas questões básicas, a norma apresenta alguns aspectos críticos, entre os quais os seguintes:

$O \S 1^{\circ}$ do Art. 31 associa a concentração de Escherichia coli com cistos de Giardia e com oocistos de Criptosporidium e o $\S 2^{\circ}$ do mesmo artigo relaciona turbidez com oocistos de Criptosporidium. Essas associações não têm suporte técnico e experimental, devendo, portanto, ser reavaliadas. Com efeito, os estudos desenvolvidos em São Paulo (ETA-A e ETA-B) (Muller, 1999), deu suporte às seguintes conclusões: (i) a ocorrência de oocistos nas amostras de água bruta não apresentou correlação com as variáveis físico-químicas avaliadas, mostrando que variáveis como $\mathrm{pH}$, turbidez, cor e alcalinidade não são indicadores adequados da presença de oocistos de Criptosporidium na água, e ; não houve, também, correlação significativa entre oocistos de Criptosporidium com $\mathrm{pH}$, alcalinidade e concentração de cloro em amostras analisadas de água tratada.
Estudos-piloto efetuados em filtração direta ascendente em areia, na Universidade de Brasília (Nascimento, 2009), concluiu, com base em análise estatística, que não houve correlação significativa entre oocistos de Criptosporidium parvum e as variáveis turbidez, coliformes totais, E. coli e contagem de partículas na água filtrada.

A adoção de turbidez ou de número de partículas presentes em uma amostra de água como variável sub-rogada para avaliar a presença de oocistos de Criptosporidium não é tecnicamente suportada. Com efeito, a concentração de oocistos é extremamente baixa em relação ao número de partículas (ou de partículas coloidais se a referência for turbidez), o que leva a uma correlação pouco significativa. Por exemplo, uma concentração de Criptosporídium de 10 oocistos por 100 litros equivale a $10^{-4}$ oocistos por $\mathrm{mL}$. Uma contagem de partículas com dimensões de $2 \mu \mathrm{m}$ ou maiores em águas com concentrações de 1.000 a 10.000 partículas por $100 \mathrm{~mL}$ leva a uma relação de 1 oocisto de Criptosporídium para $10^{7}$ a $10^{8}$ partículas. (Edzwald \& Kelley, 1998). Mesmo uma água filtrada com 100 partículas por $100 \mathrm{~mL}$ leva a uma relação de 1 oocisto para 1 milhão de partículas, mostrando a precariedade da relação pretendida. Note-se que na epidemia de Milwaukee, onde 400.000 pessoas adquiriram criptosporídíase causando 69 óbitos, ambas as estações de tratamento de água da cidade operavam com turbidez inferior a 0,45 UJT. (Mc Kenzie et al, 1994)

A grande variedade de produtos químicos que são continuamente lançados no mercado e a presença constante de poluentes emergentes em nossos recursos hídricos, a deficiência flagrante dos sistemas convencionais de tratamento de água e o fraco poder regulatório de nossas normas leva à principal dúvida levantada em relação à proteção da saúde pública, proporcionada atualmente aos usuários de sistemas públicos de abastecimento de água: $\underline{\mathrm{O}}$ atendimento completo da atual Portaria MS 2.914 de 12.12.2011 garante a distribuição de uma água segura? Seria essa garantia assegurada por uma portaria que regulamenta pouco menos de 100 variáveis, incluindo as microbiológicas, turbidez, temperatura, substâncias químicas, cianotoxinas, radioatividade e organolépticas, enquanto o mercado manipula milhões de poluentes, químicos e biológicos, que adentram nossos mananciais de água potável? É técnica e financeiramente aceitável continuar com extensivos programas de vigilância da qualidade da água, com base nessa norma, quando temos a absoluta certeza que os sistemas 
convencionais de tratamento de água não são capazes de eliminar compostos e substâncias solúveis, que estão, atualmente, presentes em nossos mananciais, em concentrações de nanogramos por litro?

Não se dispõe, atualmente, de normas e mesmo diretrizes associadas a poluentes emergentes químicos (disruptores endócrinos, fármacos, cosméticos, etc.). Não há, portanto, possibilidade de exercer uma vigilância sanitária da água potável que seja, pelo menos, parcialmente confiável. Todas as metodologias e propostas associadas à segurança da qualidade da água potável permanecerão totalmente inócuas enquanto não se adotarem sistemas de tratamento avançados, em substituição aos sistemas convencionais de tratamento atualmente praticados, que são projetados para remover apenas sólidos suspensos. Sistemas avançados de tratamento, hoje disponíveis a custos competitivos e extremamente eficientes na remoção de substâncias orgânicas e inorgânicas, mesmo as com baixos pesos moleculares de corte e em diminutas concentrações, permitem a produção de água segura, mesmo a partir de ma- nanciais desprotegidos hoje existentes em praticamente todo o Brasil. (Hespanhol, 2012)

Por outro lado, é necessário dirigir os esforços para a produção de uma norma realista para exercer a vigilância sanitária da água potável. Um critério mais adequado, que exigirá grande esforço e uma considerável introdução de recursos humanos e financeiros, mas que produziria uma norma realística, seria efetuar uma avaliação nacional, similar à que a OMS efetua quando prepara as suas diretrizes para água potável. Esta avaliação pode, resumidamente, ser operacionalizada em três fases. A primeira seria escolher quais variáveis deveriam ser regulamentadas em função da sua conspicuidade ambiental e dos níveis de riscos correspondentes. Conforme mostrado na Figura 1, as variáveis a serem escolhidas estariam incluídas no triângulo superior, ou seja, as que ocorrem com maior frequência e as que possuem maior risco intrínseco. Deveriam ser, também, avaliadas as que apresentam risco médio e ocorrência elevada.

Esta primeira fase não exigiria grandes inves-

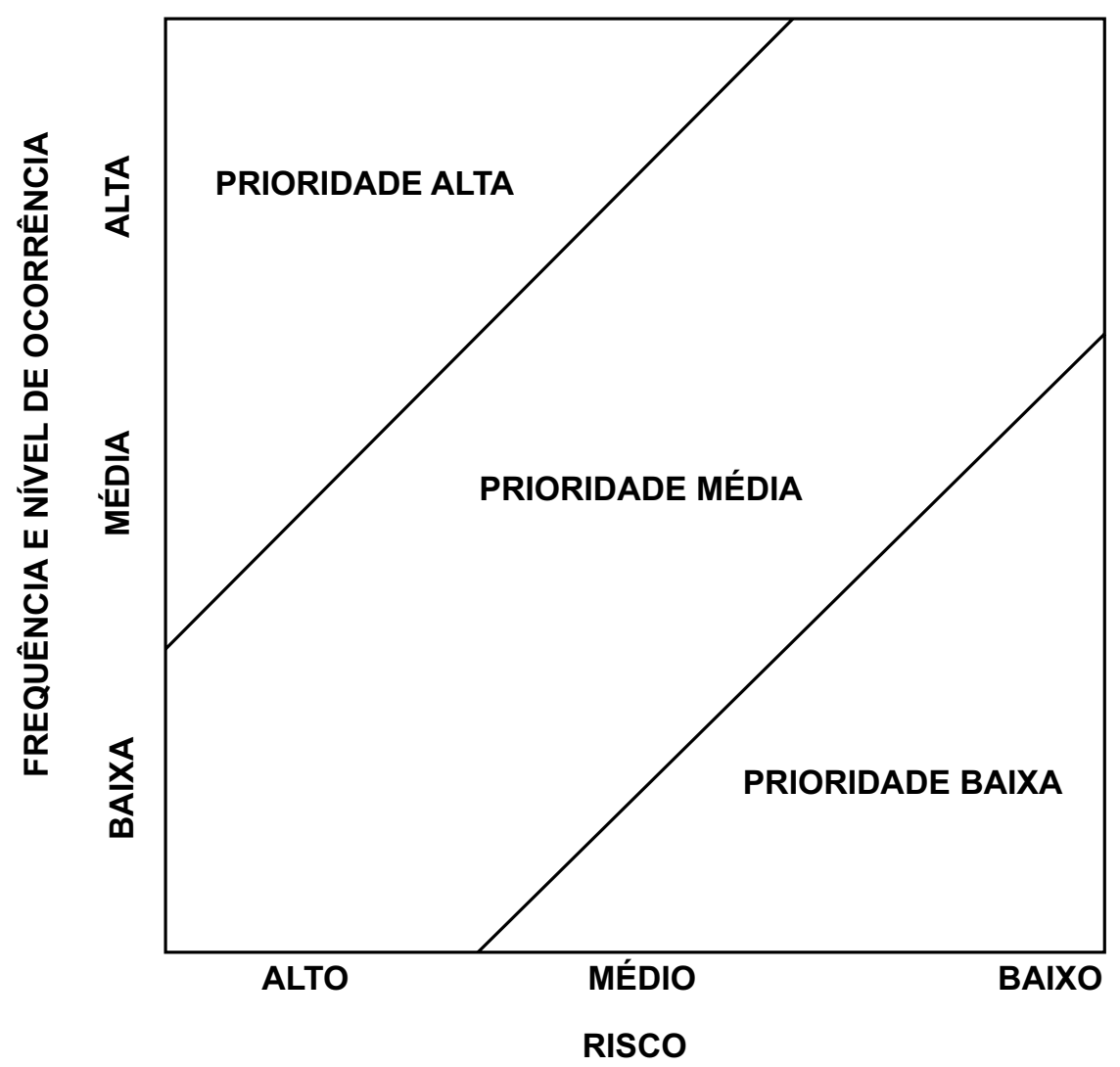

Figura 1- Critério básico para avaliação de variaveis a serem regulamentadas 
timentos e poderia ser executada em período relativamente curto de um ou dois anos, efetuando uma avaliação estatística de dados disponíveis no Ministério da Saúde (Departamento de Epidemiologia e Agência Nacional de Vigilância Sanitária - ANVISA), nas companhias estaduais de controle e gestão ambiental e de dados estatísticos de registros de incidência de doenças crônicas e transmissíveis, eventualmente disponíveis em outras fontes, tais como o Instituto Brasileiro de Geografia e Estatísticas-IBGE e outras entidades associadas a controle de endemias.

A segunda etapa, mais complexa do que a anterior, seria avaliar as respectivas doses-respostas para as variáveis definidas na primeira fase, como mostrado na Figura 2.

Esta segunda fase poderia vir a ser extremamente complexa e exigiria a elaboração de extensivos estudos toxicológicos. Entretanto, estudos internacionais efetuados, principalmente pelos centros colaboradores da OMS, dispõe de dados de dose-resposta para todas as variáveis regulamentadas pela OMS. Aquelas variáveis que fossem identificadas no Brasil e para as quais não se dispusesse de dados são as que deveriam ser avaliadas por nossos cientistas. A etapa final, que constaria da avaliação dos níveis potenciais de exposição que podem ocorrer sobre seres humanos, deveria ser desenvolvida através de estudos epidemiológicos, nos quais populações expostas aos riscos das variáveis selecionadas seriam comparadas com grupos de controle, para avaliar os excessos de risco potenciais correspondentes às doses-respostas, obtidas na segunda etapa desse estudo.

Evidentemente esses estudos demandarão longos períodos de dedicação e, devido à sua complexidade, deverão ser programados e desenvolvidos por equipes de toxicologistas e epidemiologistas altamente qualificadas, trabalhando sobre a égide do Ministério da Saúde.

Nesta etapa deverão, também, ser incluídos os poluentes emergentes que forem considerados relevantes para regulamentação. Como se dispõe de poucos dados oficiais relativos a esses compostos seria desejável efetuar um levantamento nacional sobre a sua ocorrência. A literatura nacional evidencia uma ampla ocorrência desses poluentes (Bila \& Dezotti, 2003, Cantusio Neto 2004, Daniele \& Dezotti 2003, Ghiselli, 2006, Mierzwa, 2009, Ternes et al. 1999), podendo, também, ser utilizada a literatura internacional como referência para uma primeira avaliação (Baronti et al, 2000, Karanis et al., 1998, Kolpin et al, 2002, Loos et al., 2010, Mac Kenzie et al. 1994). Nesse aspecto, é conveniente considerar a metodologia adequada de avaliação para que não ocorram falsos resultados, particularmente em relação aos elementos traços. Há uma ampla informação sobre as metodologias adequadas na literatura (Desbrow et al, 1998, Barrek et al 2009), Durán-Alvarez, 2009, Gibson et al, 2010, Gomes, 2003, Petrovic, et al., 2010). Enquanto métodos como o ELISA (ensaio imuno-absorvente associado a enzimas) não têm apresentado resultados confiáveis devido ao seu baixo limite de detecção (20 a 40 ng/L), os que permitem grande confiabilidade são os GC-MS/MS (cromatografia

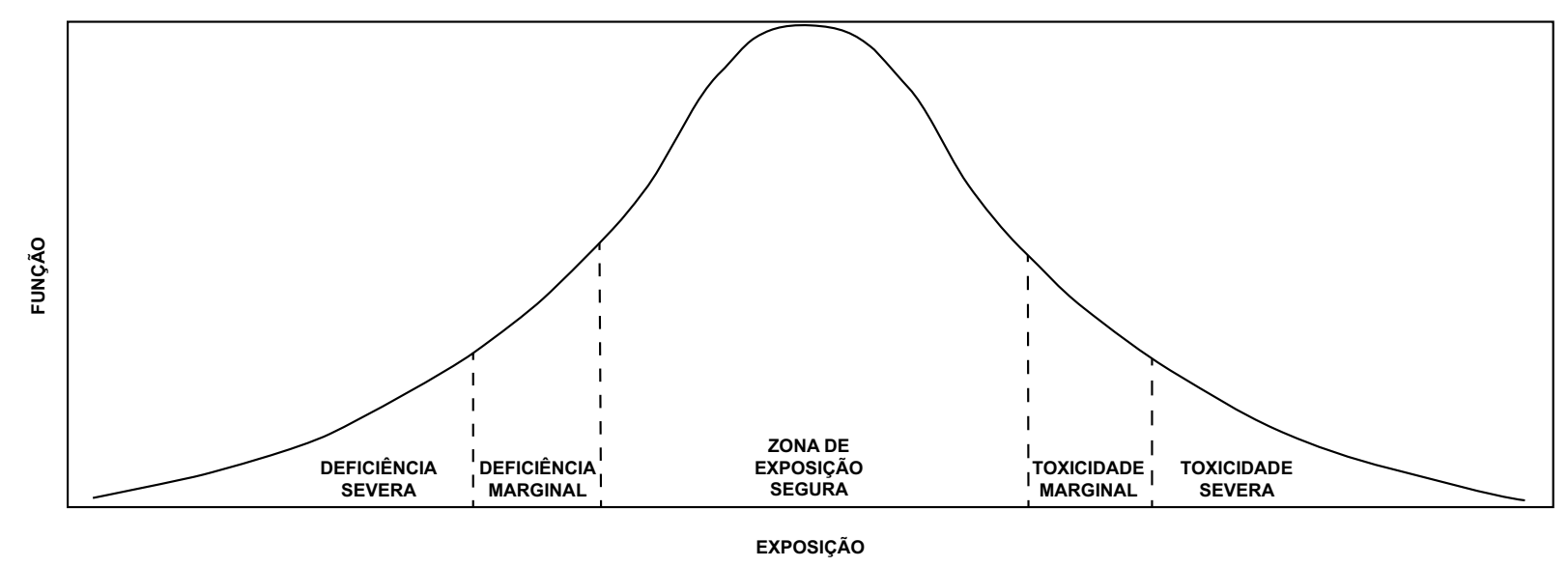

Figura 2- Curva dose - resposta 
a gás, espectrômetro de massa/espectrômetro de massa e SPME-HPLC (microextração em fase sólida e cromatografia líquida de alto desempenho), com limites de detecção de 0,05 a 2,4 ng/L e 0,064 a 2,4 ng/L (Chang et al., 2009)

\section{A portaria das Secretarias para re- úso urbano.}

As propostas incluídas na Consulta Pública 04/2013 relativa à "Minuta de Resolução Conjunta SS/SMA/SRHS: Proposta de disciplinamento do Reúso Direto não Potável de Água Proveniente de Estações de Tratamento de Esgoto Sanitário para Fins Urbanos", seguem a mesma filosofia de adotar, sem análises comparativas ou adaptação às condições locais, normas de países altamente industrializados e/ou diretrizes da OMS. Além disso, tendem a restringir práticas usuais que em vez de serem excluídas deveriam ser adequadamente regulamentas. O termo "norma" vem do vocábulo "normal", isto é, deve ser associado e incluir práticas tradicionais existentes em uma determinada sociedade. Estas deverão ser consolidadas e regulamentadas e não impedidas de ser praticadas. Outros critérios devem ainda ser considerados para efeitos de regulamentação. Embora a saúde pública dos grupos de risco seja de extrema importância, não devem ser relegados os importantes aspectos econômicos do reúso, assim como aqueles associados à mitigação de condições de estresse hídrico, como o que assola a Região Metropolitana de São Paulo.

Há que considerar que os sistemas tradicionais de tratamento de esgotos utilizados no Brasil (lodos ativados convencionais ou com aeração prolongada) não são capazes de produzir efluentes com qualidade para atender aos padrões estabelecidos na proposta. Mesmo com um tratamento físico-químico complementar (coagulação, floculação, sedimentação, filtração e desinfecção com cloro) não seriam atendidas algumas das variáveis listadas, tais como DBO, Cor, Ovos de Helmintos, Protozoários e Metais. Os sistemas de lagoas de estabilização, também bastante utilizados no Brasil, poderiam, se constituídos com pelo menos três compartimentos em série e unidades de maturação, atingir os padrões estabelecidos para as variáveis Ovos de Helmintos e Coliformes Fecais, mas não atenderiam às demais variáveis.
A proposta apresentada pelas Secretarias foi intensamente criticada por especialistas ambientais e principalmente por usuários de sistemas de reúso urbano, que demonstraram não ter condições de atender às grandes e injustificadas restrições impostas, as quais contribuiriam apenas para inibir a prática do reúso urbano. Esta regulamentação deverá, portanto, ser totalmente revisada, tanto em termos de variáveis regulamentadas e respectivos valores numéricos, quanto em termos de sistemas de tratamento adequados, aspectos econômicos e regionais, para permitir uma efetiva implementação da prática de reúso de água no Estado de São Paulo. Deve ser considerado, ainda, que as normas e códigos de prática promulgados no Estado de São Paulo sejam extremamente visíveis e considerados em muitas partes do Brasil, onde as condições de implementação são ainda mais críticas. Apresentam, portanto, um efeito negativo potencial ainda mais pronunciado em termos de restrição à prática de reúso, uma vez que uma parte significativa dos demais estados brasileiros não possui condições técnicas e econômicas para atender a padrões e especificações tão restritivas e dissociadas da realidade brasileira.

Por outro lado, regulamentações que envolvem aspectos de saúde pública não podem ser elaboradas exclusivamente em "nível de gabinete" no qual profissionais se reúnem para definir, aleatoriamente, variáveis a serem regulamentadas e respectivos valores numéricos. O Brasil já tem condições de ultrapassar esta fase imediatista, elaborando normas e códigos de prática baseados em levantamentos das condições reinantes no país, e em estudos epidemiológicos e toxicológicos semelhantes aos relacionados acima sobre a regulamentação para água potável.

\subsection{Ovos de Helmintos (Nematodos Intestinais)}

$\mathrm{Na}$ reunião de especialista da OMS sobre reúso de esgotos e excreta na agricultura e aquicultura realizada em 1985 na cidade de Engelberg, Suíça, (IRCWD, 1985), foi estabelecida a diretriz para irrigação restrita e irrestrita de $\leq 1$ ovo viáveis de nematodos intestinais por litro (média aritmética durante o período de irrigação).

O grupo de especialistas da OMS que se reuniu em Genebra, Suíça, em 1989, estabeleceu 
novas diretrizes para o uso de águas residuárias na agricultura e na aquicultura (WHO, 1989). Nesta reunião, da qual este autor participou como organizador do evento e como membro do corpo científico da OMS, foi mantida, com base em uma grande quantidade de estudos epidemiológicos (Shuval et al, 1986) a diretriz de $\leq 1$ ovo de nematodos intestinais por litro, mas eliminou, por decisão unânime dos participantes, o termo viável que havia sido proposto na reunião de Engelberg. Esta decisão foi baseada na consideração de que a eliminação da caracterização de viabilidade viria a favor da segurança, permitindo, ainda, a redução dos custos das análises correspondentes.

Na reunião subsequente sobre o tema, realizada na sede da OMS em Genebra, em 2006 (WHO, 2006) foi efetuada a revisão das diretrizes estabelecidas em 1989. Nesta reunião foi proposto, por alguns membros de países altamente desenvolvidos, particularmente a professora Ursula Blumenthal, da London School of Hygiene and Tropical Medicine, e o professor Duncan Mara, da Leeds University, a redução da diretriz de ovos de Helmintos em uma ordem de magnitude, isto é, de $\leq 1$ ovo/L para $\leq 0,1 \mathrm{ovo} / \mathrm{L}$. Esta proposta foi baseada em um estudo epidemiológico preliminar (Blumenthal, U, 2000) realizado no Vale do Mesquital, no México, uma área onde, devido à irrigação de culturas com esgotos brutos, ocorre grande incidência de doenças parasitárias provocadas, principalmente, por áscaris lumbricoides. $O$ estudo aborda a infestação de crianças menores do que 15 anos que brincam, descalças, em campos agrícolas irrigados com esgotos

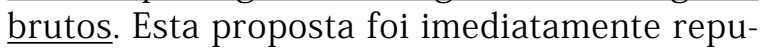
diada por todos os participantes de países em desenvolvimento, inclusive por este autor, que participou da reunião na condição de consultor da OMS. Em face dessa reação foi mantido o valor de diretriz de $\leq 1$ ovo/L, tanto para irrigação restrita como irrestrita. Entretanto, devido à grande pressão exercida por membros de países industrializados, onde, ironicamente, não há ocorrência de doenças parasitárias, foi introduzida uma observação na relação das diretrizes, especificando que "quando crianças menores de 15 anos de idade são expostas, medidas adicionais de proteção devem ser adotadas, como por exemplo tratar os efluen- tes para atingir $\leq 0,1$ ovo/L e utilizar equipamentos protetores, tais como luvas, botas ou aplicação de tratamento quimioterápico". Verifica-se portanto que essa especificação complementar, além de ser desenvolvida em bases muito preliminares, refere-se a uma área onde ocorre alta infestação por ovos de Helmintos e, ainda, em associação a áreas de extensa irrigação agrícola onde há demanda de equipamentos especiais para proteção dos grupos de risco, e não para irrigação de quadras esportivas, parques e jardins.

A tendência de adotar, indiscriminadamente, valores numéricos sempre os mais restritivos encontrados na literatura, mesmo sem considerar que as condições nas quais esses valores foram obtidos são completamente diferentes daquelas para as quais foram formulados. Neste caso, os argumentos que especificam 0,1 ovo/L não são característicos das nossas condições as mais críticas possíveis, mesmo quando a irrigação com esgotos tratados é efetuada em gramados utilizados para "play grounds". Além de ser valores obtidos sem um suporte epidemiológico adequado, representam características de áreas onde ocorre grande infestação e, associados, especificamente à irrigação de culturas, onde há uma intensiva aplicação de efluentes brutos durante uma grande parte do ano.

Há que se considerar ainda que, além de exigir um nível de tratamento mais avançado para atender à condição de $\leq 0,1$ ovo/L, haveria um aumento dos custos das análises (avaliado em 10 a $15 \%$ ) e a necessidade de grandes volumes de amostras para validar, com segurança, a presença de ovos de Helmintos.

Em face das considerações acima seria adequado manter o valor numérico de $\leq 1$ ovo/L e não de $\leq 0,1$ ovo viável/L de nematodos intestinais.

\subsection{Protozoários}

Uma grande parte das críticas efetuadas à proposta das Secretarias são as relativas à inclusão de cistos de Giardia e oocistos de Criptosporídeo. Esta proposta não tem sustentação científica e operacional, uma vez que a única rota de transmissão associada a esses protozoários é por via oral, cuja ocorrência é pouco provável nos usos permitidos. Avaliações epidemiológicas devem ser efetuadas nas condi- 
ções brasileiras, mas estudos elaborados no exterior com Criptosporídeos, por exemplo, indicam que a ingestão involuntária de pequenas doses levam a um risco superior a um AVAD de $10^{-4}$ pppa (Ryu et al., 2007), isto é, a um caso adicional de infecção por Criptosporídeos para um grupo de risco de 10.000 pessoas. Entretanto, a proposta deste autor para irrigação irrestrita (condição muito mais crítica do que a irrigação de parques e jardins) de um AVAD de $10^{-4}$ pppa é considerada como aceitável nas condições brasileiras (Hespanhol,2009). A ingestão de pequenas doses não leva à contaminação por oocistos de criptosporídeos. Estudos efetuados com voluntários com boa saúde (Dupont et al, 1995) indicaram que a dose infectiva de Criptosporidium parvum é de 132 oocistos (DL 50). Nessas condições, assumindo o valor normativo proposto de 0,25 oocistos/L, seria necessário ingerir, de uma vez, 538 litros do efluente tratado. Mesmo que a concentração fosse de 10 oocistos/L seria necessário ingerir, de uma vez, 13,2 litros de efluente tratado para causar a infecção em 50\% dos componentes do grupo de risco correspondente. Outros autores (Okhuysen et al, 1999 e Ochiai, Y et al, 2005) avaliaram que a DL 50 obtida em estudos efetuados, também com voluntários de boa saúde, varia entre 10 e 1.000 oocistos, dependendo da cepa de c. parvum considerada. Pelo fato de que nossa população seja, em sua maioria, constituída por indivíduos com sistemas imunológicos não necessariamente adequados seria extremamente importante a realização de estudos epidemiológicos antes de adotar um valor padrão, tanto para Criptosporídeos como para as demais variáveis incluídas na proposta das Secretarias. A necessária segurança adicional viria através da emissão de um correspondente código de prática, que deveria acompanhar a proposta. Esta modalidade de reúso deveria, por exemplo, exigir a colocação de avisos, indicando que a água não é potável e especificar a utilização de torneiras de acionamento com chave para evitar que a água de reúso seja utilizada como potável.

\subsection{Metais e Sódio}

As variáveis e respectivos valores numéricos de metais relacionados para Classe A foram copiados diretamente da publicação da FAO sobre tratamento de esgotos para uso na Agri- cultura (FAO, 1992). As únicas exceções são para o Boro (em que a FAO recomenda $\leq 0,7$ $\mathrm{mg} / \mathrm{L}$ (para irrigar sem restrições para essa variável) e para o Chumbo que é recomendado $5,0 \mathrm{mg} / \mathrm{L}$ pela FAO e na tabela para Classe A é indicado 0,50 mg/L. Aparentemente, esta diferença de uma ordem de magnitude para o Chumbo teria sido causada por erro de transcrição. Certamente não foi considerado que as variáveis regulamentadas pela FAO e seus respectivos valores numéricos foram elaborados para quando é efetuada irrigação para produção de alimentos. A Tabela 10, na página 17 , de onde foram copiadas as variáveis, especifica claramente "Threshold levels of trace elements for crop production" e não "para irrigação paisagística... de caráter esporádico ou sazonal", como especificado na proposta das Secretarias. É necessário, inclusive, verificar se metais pesados devem ser regulamentados em face de aplicações de efluentes tratados apenas periódica ou sazonalmente. Se, após uma avaliação consistente, esta necessidade for comprovada, as variáveis e respectivos valores numéricos deverão ser adotados com procedimentos similares aos apresentados no item sobre aplicação de biossólidos, mas, desta vez, em associação apenas a efeitos sobre o solo e sobre eventuais aquíferos freáticos existentes no local de aplicação.

A variável sódio deverá, também, ser reavaliada, pois mesmo com sistemas de membranas de ultrafiltração é difícil atingir a concentração de $69 \mathrm{mg} / \mathrm{L}$, tratando esgotos domésticos. Considere-se, ainda, que a Portaria MS 2914/2011 especifica um valor numérico para a variável Sódio igual a $200 \mathrm{mg} / \mathrm{L}$, o que tornaria ilegal a aplicação de água potável para irrigação paisagística. Entretanto, em se tratando de irrigação, mesmo para fins paisagísticos o cloro é pouco significativo se for tratado independentemente de outras variáveis, ou seja, Cálcio e Magnésio, que atenuam seus efeitos negativos sobre o solo. Nesse sentido, é lamentável que a proposta normativa tenha considerado apenas o Sódio, deixando de considerar a importante variável composta Razão de Adsorção de Sódio, (SAR em me/L) que em valores elevados provoca a floculação do solo, evitando que água e ar atinjam os níveis das raízes, eliminando, portanto, os efeitos benéficos da irrigação. Para plantas que não apre- 
sentam grandes restrições ao uso de Sódio, o SAR pode permanecer em valores inferiores a $3 \mathrm{me} / \mathrm{L}$. Este valor deve, entretanto, ser verificado para solos e vegetações típicas das existentes no Estado de São Paulo.

\subsection{Lavagem de veículos}

A utilização de água de reúso para lavagem de veículos é uma atividade de grande importância para a conservação de recursos hídricos, particularmente em áreas de estresse hídrico como a RMSP. Por exemplo, apenas duas das maiores empresas de transporte urbano de São Paulo lavam cerca de mil ônibus por dia, utilizando aproximadamente 400 litros de água por ônibus. Uma grande empresa nacional, que opera na distribuição de combustíveis, coordena a operação de 6.000 postos de serviço (urbanos, de rodovia e de clientes consumidores que compram gasolina e óleo diesel a granel), dos quais aproximadamente 700 são designados como Postos Ecoeficientes. Nesses postos estão sendo instalados sistemas de tratamento avançado para aproveitamento de águas pluviais e reúso de efluentes para a lavagem de quaisquer tipos de veículos, sem restrição.

A restrição à lavagem de veículos comuns eliminará, certamente a alternativa que os postos de serviço teriam de avaliar economicamente a utilização de água de reúso oriunda das estações de tratamento, em relação aos sistemas de tratamento e reúso instalados internamente. Teme-se, ainda, que a restrição de lavagem de veículos comuns, imposta ao reúso de efluentes oriundos de estações de tratamentos de esgotos seja, também, estendida ao reúso após tratamento efetuado nos próprios postos de serviço. Por outro lado, a proibição da prática de lavagem interna de veículos é irracionalmente restritiva. As águas da Classe B destinadas a esta modalidade de reúso restringem a variável E. Coli a um valor igual ou inferior a $200 / 100 \mathrm{~mL}$, enquanto que a Resolução CONAMA 274/2000 considera como excelente o valor máximo para balneabilidade (que inclui a prática de esportes de contato primário, com imersão total) de 250 E. Coli/100 mL, como muito boa com a concentração de 500 E.Coli/100 mL, e como aceitável a concentração de $1.000 \mathrm{UFC} / 100 \mathrm{~mL}$.

\subsection{Reúso em edificações e Reserva de incêndio}

A prática de reúso em edificações para descarga em bacias sanitárias, lavagem de pisos e irrigação vem sendo utilizada em larga escala no Brasil, tanto em edifícios públicos como em edifícios corporativos. Quando utilizada apenas para descarga sanitária permite uma redução do consumo de água em torno de 30\%. Se, além disso, o reservatório de água de reúso abastece as demandas para lavagem de pisos externos, garagens e irrigação de áreas verdes, a economia no consumo de água pode chegar a 80\%. A função da legislação é regulamentar práticas consolidadas e não de impedir a sua implementação. Essa prática deverá ser regulamentada, permitindo o emprego de águas de reúso de Classe $B$, uma vez que a concentração de coliformes fecais eventualmente contidos em aerossóis produzidos durante a fase de descarga teria, como proposto, uma concentração máxima de 200/100 mL, abaixo portanto do padrão de balneabilidade conforme discutido no item 5.4 .

A utilização de água de reúso para reserva de incêndio não foi, também, considerada na proposta de resolução das Secretarias. O argumento básico para negar a prática é evitar a contaminação de eventuais moradores presentes durante o apagamento de incêndios. A experiência mostra que, durante esses tipos de sinistros, é pouco provável que as águas utilizadas atinjam vítimas diretamente e que os maiores volumes de água sejam utilizados para operações de rescaldo. Entretanto, mesmo assumindo que haja contato humano, a reserva de incêndio com água de reúso poderia ser empregada com águas da Classe B, que apresentam uma concentração máxima de coliformes fecais de 200/100 mL, valor muito abaixo do tolerado para imersão total em sistemas aquáticos.

\subsection{Recarga gerenciada de aquíferos}

A regulamentação de recarga gerenciada de aquíferos, não incluída na presente proposta, seria de extrema importância para o Brasil, por se constituir em um instrumento adicional para dar suporte à gestão de recursos hídricos, particularmente em áreas de estresse hídrico e onde ocorrem conflitos pelo uso da água.

A recarga gerenciada de aquíferos, vista como uma modalidade de reúso, pode atender 
a uma gama significativa de objetivos, entre os quais proporcionar tratamento adicional de efluentes, aumentar a disponibilidade de água em aquíferos potáveis ou não potáveis, proporcionar reservatórios de água em substituição a reservatórios superficiais, servir como um eventual sistema de distribuição, permitindo eliminar a construção de adutoras, evitar ou controlar subsidência de solos e prevenir a intrusão de cunha salina em aquíferos costeiros. (Hespanhol, 2009a e Hespanhol, 2012a)

Os sistemas de recarga gerenciada relacionados em seguida são apenas alguns exemplos das centenas de sistemas em operação contínua, produzindo água para diversos usos benéficos: Região do Dan, em Israel, irrigação irrestrita e água potável; Atlantis, África do Sul, água potável; Berlin, Alemanha, água potável; Tucson e Phoenix, Arizona, Estados Unidos, controle de subsidência de solos, irrigação de parques, jardins e campos de golfe; Orange County, Califórnia, Estados Unidos, proteção contra intrusão salina e água potável; Torreles, Bélgica, água potável; Sabadell, Espanha, irrigação de parques; Hals Head, Austrália, irrigação urbana; Windhoek, Namíbia, água potável; Nova Dehli, Índia, irrigação; Nardó, Silento, Itália, água potável e não potável; e Gaobeidian, Beijing, China, potável.

Estudos de recarga gerenciada efetuados em todo o mundo mostram a grande eficiência com que camadas insaturadas existentes nas partes superiores de aquíferos promovem a remoção de poluentes tradicionais, assim como de fármacos e disruptores endócrinos. (Kreusinger et al., 2010 e Arnold, 2009)

Um pequeno programa de visitas por parte de profissionais de agências reguladoras do saneamento a alguns desses sistemas evidenciaria os grandes benefícios que proporcionam, assim como a extrema segurança com que operam, em termos de proteção dos aquíferos submetidos aos processos de recarga gerenciada.

\subsection{A palavra "reúso"}

A palavra "reúso" não constava, até 1998, na língua portuguesa e até então era traduzida literalmente do inglês e escrita de duas formas re-uso ou reuso. A grafia certa é "reúso", do verbo "reusar" devendo ser acentuada por ser um hiato.
Especulava-se que, com a reforma ortográfica, o acento teria desaparecido, mas na verdade só desapareceu em palavras que possuem "i" ou "u" como parte de um hiato, se for precedido de um ditongo (ou seja, precisa-se de 3 vogais juntas), como, por exemplo, em "feiura" (fei-u-ra) que pela regra nova não possui mais acento no "u". A palavra "reúso" não tem hífen mas tem o acento gráfico para marcar a sílaba tônica no U. Sem o acento o EU seria pronunciado como ditongo / reu/, e não como hiato, em que o U é pronunciado sozinho numa sílaba: /re-ú-so/. Se fosse grafado como *reuso, poderia ser lido como /reuso/ como se lê deusa ou Neusa.

\section{Conclusões e recomendações}

O objetivo básico de normas e códigos de prática, particularmente as relativas a aspectos de saúde pública é estabelecer instrumentos de gestão, atribuindo valores numéricos realísticos a variáveis localmente significativas, com a finalidade de dar suporte a sistemas operacionais de comando e controle, associados à realidade e características de cada região ou país onde o controle é exercido. Devem, também, ser dirigidas à regulamentação de práticas existentes sem ter, absolutamente, o direito de impedir a implementação daquelas já consolidadas, tais como a aplicação de biossólidos como condicionantes de solos, reúso para fins não potáveis em edificações, lavagem de veículos comuns e reserva de incêndio.

Há que se considerar, ainda, que regulamentações que envolvem aspectos de saúde pública não podem ser elaboradas exclusivamente em "nível de gabinete" onde profissionais se reúnem para definir, aleatoriamente, variáveis a serem regulamentadas e seus respectivos valores numéricos. O Brasil já tem condições de ultrapassar esta fase imediatista e passar a elaborar normas e códigos de prática baseados em levantamentos das condições reinantes no país, e em estudos epidemiológicos e toxicológicos.

No estabelecimento de diretrizes associadas a aspectos de saúde pública, a Organização Mundial da Saúde identifica como "provisionais" os valores numéricos estabelecidos para variáveis sobre as quais não dispõe de estudos específicos nem de dados suficientes produzidos por estudos epidemiológicos ou to- 
xicológicos. Como esta é, também, a realidade brasileira, seria adequado que as normas aqui desenvolvidas fossem, igualmente, designadas como provisionais até que se definam valores mais significativos de nossas condições ambientais e de saúde pública, baseada em uma metodologia cientificamente defensável que permita montar uma legislação realista para água potável, biossólidos e água de reúso.

Paralelamente, para efetivamente proteger a saúde pública dos grupos de risco, deveria ser exigido o emprego, para a produção de água potável e de água de reúso, das melhores tecnologias disponíveis, já consagradas internacionalmente e no Brasil.

Estudos desenvolvidos no CIRRA (Mierzwa, 2009) mostraram a eficiência da remoção de disruptores endócrinos e de microcistina utilizando sistemas de membranas de ultrafiltração. A sugestão básica é que sejam estudados, para ser aplicados dentro de nossas condições esses tipos de sistemas, complementados com sistemas empregando processos oxidativos avançados. A literatura internacional mostra que processos oxidativos avançados, utilizando peróxido de hidrogênio e radiação ultravioleta (Rosenfeldt, et al., 2004, Huber et al., 2003) ) são bastante efetivos na remoção de traços de fármacos e disruptores endócrinos eventualmente remanescentes de sistemas de membranas de ultrafiltração utilizados para produção de água potável.

Da mesma maneira, algumas de nossas companhias de saneamento, exatamente aquelas capacitadas para fornecer águas de reúso para fins não potáveis, já implantaram ou estão considerando a implantação de sistemas avançados de tratamento de esgotos domésticos, utilizando sistemas de biomembranas (MBRs) equipados com membranas de ultrafiltração (poros com dimensões entre 0,001 $\mu \mathrm{m}$ e $0,1 \mu \mathrm{m})$. Esses sistemas permitem a produção de efluentes com qualidades superiores aos das Classe A e B relacionadas na proposta das Secretarias. Com exceção de Sódio, e de alguns outros elementos e compostos de baixa massa molecular de corte, permitem obter, consistentemente, efluentes com baixa carga orgânica e livres de protozoários, coliformes e vírus, sem a necessidade de posterior desinfecção. Os sistemas convencionais de lodos ativados existentes, que, certamente, não têm condições de produzir efluentes com valores numéricos de diversas variáveis contidas na proposta das Secretarias (como, por exemplo, ovos de Helmintos, cistos de Giardia e oocistos de Criptosporídeos) podem ser facilmente adaptados para operar como MBRs, através da substituição dos decantadores secundários por unidades de membranas de ultrafiltração, instalados nas próprias câmaras de aeração.

\section{Referências bibliográficas}

Arnold, R., (2009), Residuals Organics and Ammonia Nitrogen During SAT of Conventionaly Treated Municipal Wastewaters, Workshop Uso e Reúso de Águas Residuárias, Sabesp, São Paulo, 13 de maio.

Baronti, C., Curine, R., D’Ascenzo, G., Di Corcia, A., Gentili, A., Samperi, R., (2000), Monitoring Natural and Synthetic Estrogens at Activated Sludge Sewage Treatment Plants and in a Receiving River Water, Environmental Science and Technology, vol.34, $n^{\circ} 24$, p. 5059-5065.

Barrek, S., Cren-Olivé, C., Wiest, L., Baudot, R., Arnaudguilhem, C., Grenier-Loustalot, M., (2009), Multi-residue analysis and ultra-trace quantification of 36 priority substances from the European Water Framework Directive by GC-MS and LC-FLD-MS/MS in surface waters, Talanta 79, p.712-722, Journal homepage:www.elsevier.com/locate/talanta.

Bila, D.M., Dezotti, M., (2003) Fármacos no Meio Ambiente, Quim. Nova, vol.26, $\mathrm{n}^{\circ} 4$, p.523-530.

Blumenthal, U, (2000) Guidelines for wastewater reuse in agriculture and aquaculture: recommended revisions based on new research evidence, Water and Environmental Health at London and Loughborough and London School of Hygiene and Tropical Medicine (WELL Study Task no. 68, Part 1.

Cantusio Neto, R., (2004), Ocorrência de oocistos de Cryptosporidium spp. e cistos de Giardia spp. em diferentes pontos do processo de tratamento de água em Campinas-SP, p. 82, Tese para obtenção do título de Mestre em Parasitologia, Instituto de Biologia, Universidade Estadual de Campinas, Campinas, SP. 
Chang, A.C., Page, A.L. e Asano, T., (1995), “Developing Human Health-Related Guidelines for Reclaimed Wastewater and Sewage Sludge Applications in Agriculture", WHO/EOS/95.20, 114 pp., World Health Organization, Geneva.

Chang,A.C., A. L. Page, Asano, T, e Hespanhol, I., (1998), "Evaluating Methods of Establishing Human Health-Related Chemical Guidelines for Cropland Application of Municipal Wastewater", in: Wastewater Reclamation and Reuse, vol.10, Chapter 13, pp.581-626, Ed. T. Asano, Technomic Publishing Co., Inc., Lancaster, Basel.

Chang, H, Choo, K, Lee, B., Choi, S., (2009), The methods of identification, analysis and removal of endocrine disrupting compounds (EDCs) in water, Journal of Hazardous Material, 172, p.1-12. (analisis- Elisa)

Daniele, M.B., Dezotti, M., (2003), Fármacos no Meio Ambiente, Quim. Nova, vol. 26, p. 523530, Rio de Janeiro, RJ.

Desbrow, C, Routledge, E.J., Brighty, G.C., Sumpter, J.P., Waldock, M., (1998), Identification of Estrogenic Chemicals in STW Effluent. 1. Chemical Fractionation and in Vitro Biological Screening, Environmental Science and Technology, vol.32, no 11 , p. 1549-1558.

Dupont H.L., Chappell, C.L., Sterling, C.R., Okhuysen, Rose, J.B., Jabukowsky. (1995), The infectivity of cryptosporidium parvum in healthy voluenteers, N.Eng.J. Med., 332, pp 855859.

Durán-Alvarez, J.C., Becerril-Bravo, E., Silva Castro, V., Jiménez, B., Gibson, R., (2009), The analysis of a group of acidic pharmaceuticals, carbamapezine, and potencial endocrine disrupting compounds in wastewater irrigated soils by gas chromatograpgy-mass spectometry, Talanta 78, p.1159-1166, Journal homepage:www.elsevier.com/locate/talanta.

Edzwald, J.K., Kelley, M.B., (1998), Control of Cryptosporidium: From Reservoirs to Clarifiers to Filters, Water Science and Technology, Vol. 37, no. 2, p. 1-8.

Environmental Protection Agency - EPA, (2011), 2011 Edition of the Drinking Water
Standards and Health Advisories, EPA 820-R11-002, Office of Water, U.S, Environmental Protection Agency, p. 12, October, Washington, DC, USA.

FAO (1992), Wastewater Treatment and Use in Agriculture, FAO Irrigation and Drainage Paper $\mathrm{n}^{\circ} 47$, by M.B. Pescod, Food and Agriculture Organization of the United Nations, p.125, Rome.

Galal-Gorchev, H., (1991), "Dietary Intake of Pesticide Residues, Cadmium, Mercury and Lead", Food Additives and Contaminants, no.8, pp. 793-806.

Ghiselli, G., (2006), Avaliação da qualidade das águas destinadas ao abastecimento público na região de Campinas: Ocorrência e Deterioração de Interferentes Endócrinos (IE) e Produtos Farmacêuticos e de Higiene Pessoal (PFHP), Tese de Doutoramento, Área de Química Analítica, Instituto de Química, Universidade Estadual de Campinas, 25 de setembro, Campinas, SP.

Gibson,R., Durán-Álvarez, J.C., Estrada, K.L., Chávez, A., Cisneros, B.J., (2010), Accumulation and leaching potential of some pharmaceuticals and potential endocrine disruptors in soils irrigated with wastewater in the Tula Valey, Mexico, Chemosphere 82, p. 1437-1445, journal homepage:www.elsevier/locate/chemosphere.

Gomes, R.L., (2003), Determination of Endocrine Disrupters in Sewage Treatment and Receiving Waters, Trends in Analytical Chemistry, vol.22, n 10 , p.597-707, Elsevier, B.V.

Hespanhol, I., Prost, A.M.E., (1994), WHO Guidelines and National Standards for Reuse and Water Quality, Water Research, vol.28, no.1 p.119-124, Great Britain.

Hespanhol, I., (2002), "Saúde Pública e Reúso Agrícola de Esgotos e Biossólidos”, Cap. VII, pp. 75-87, in: "Reuso de Água”, Mancuso, P.C.S.,Santos, H.F., Eds., 430 pp, Editora Manole, São Paulo.

Hespanhol, I., (2009), "Viabilidade de um AVAD não superior a $10^{-4}$ por pessoa por ano, para reúso agrícola de água, em países em de- 
senvolvimento", Ambi-Água, An Interdisciplinary Journal of Applied Science, v. 4, n.2, pp 124-134/

Hespanhol, I., (2009a), O Princípio da Precaução e a Recarga Gerenciada de Aquíferos, ensaio, p.28-29, Revista DAE, $n^{\circ} 179$, ISSN 0101-6040, janeiro, São Paulo;

Hespanhol, I., (2012), "Poluentes Emergentes, Saúde Pública e Reúso Potável Direto", cap.20, p.501-537, in: Engenharia Ambiental - Conceitos, Tecnologia e Gestão, Coords. Maria do Carmo Calijuri e Davi Gasparian Fernandes Cunha, p. 789, Elsevier Campus. ISBN: 97885-352-5954-4

Hespanhol, I., (2012a), "Recarga Gerenciada de Aquíferos: Os casos do Avra Valey e do Sweetwater no Arizona e do Aeroporto Internacional de São Paulo, Guarulhos”, p. 29-78, in: Uso Eficiente da Água em Aeroportos, Eds. Wilson Cabral de Souza Júnior e Elaine Nolasco Ribeiro, Editora Rima, p. 307, São Carlos, SP.

Huber, M.M., Canonica, S, Park, G., and von Gunten, U., (2003), Oxidation of Pharmaceuticals during Ozonation and Advanced Oxidation Processes, Environmental Science and Technology, vol. 37, no. 5, p.1.016-1.024.

IRCWD, (1985), Health Aspects of wastewater and excreta use in agriculture and aquaculture , The Engelberg Report, International Reference Centre for Waste Disposal-IRCWD news, Duebendorf, Switzerland, 10 p;

Kabata-Pendias, A. e Pendias, H., (1984), “Trace Elements in Soil and Plants", CRC Press, Boca Raton, Florida, 315 pp.

Karanis, P., Schoenen, D., Seitz, H.M., (1998), Distribution and removal of Giardias and Cryptosporidium in water supplies in Germany, Water Science and Technology, vol.37, no. 2, p. 9-18

Kolpin, D.W., Furlong, E.T., Meyer, M.T., Thurman, E.M., Zaugg, S.D., Barber, L.B., Buxton, H.T., (2002), Pharmaceuticals, Hormones, and other Organic Wastewater Contaminants in U.S. Streams, 1999-2000: A National Reconnaissance, Environmental Science and Technology, vol. 36, nº 6, p.1202-1211
Kreuzinger, N. et all, (2010), Investigation on the Behaviour of Selected Pharmaceuticals in the Groundwater after Infiltration of Treated Wastewater, Institute for Water Quality and Waste Management, Viena University of Technology, Austria.

Loos, R., Locoro, G., Contini, S., (2010), Occurrence of polar organic contaminants in the dissolved water phase of the Danube River and its major tributaries using SPE-LC-MS ${ }^{2}$ Analysis, Water Research, 44, p. 2325-2335

Mac Kenzie, W.R., Hoxie, N.J., Proctor, M.E., Gradus, M.S., Blair, K.A., Peterson, D.E., Kazmierczak, J.J., Addiss, D.G., Fox, K.R., Rose, J.B. and P. Davis, J.P., (1994), A Massive outbreak in Milwaukee of Cryptosporidium infection transmitted through the public water supply, New England Journal of Medicine, vol. 331, no. 3, July, p; 161-167.

Mierzwa, J.C. (2009), "Desafios para o tratamento de água de abastecimento e o potencial de aplicação do processo de ultrafiltração", tese apresentada à Escola Politécnica da Universidade de São Paulo para a obtenção do Título de Livre-Docente, pelo Departamento de Engenharia Hidráulica e Ambiental, p.127. São Paulo, SP.

Muller, A.P.B., (1999, Detecção de oocistos de Criptosporidium spp. em águas de abastecimento superficiais e tratadas na RMSP, tese apresentada ao Instituto de Ciências Biomédicas, USP, para obtenção do título de Mestre em Ciências (Microbiologia), p;109, São Paulo, SP.

Nascimento, M.F, (2009), Remoção de oocistos de cryptosporidium por meio de filtração direta ascendente em areia: avaliação em escala piloto, dissertação de Mestrado em Tecnologia Ambiental e Recursos Hídricos, Departamento de Engenharia Civil e Ambiental, Universidade de Brasília, p.131, Brasília, D.F.

Ochiai, Y., Takada, C., Hosaka, M., (2005), Detection and discrimination of of cryptosporidium parvum e c. hominis in water samples by Immunomagnetic separation-PCR, Appl. Env. Microbiology, $n^{\circ} 71$, pp 898-903. 
O Estado de São Paulo, (2011), página C1, quinta-feira, 26 de maio de 2011

O Estado de São Paulo, (2011-a), página C3, quinta-feira, 26 de maio de 2011

O Estado de São Paulo, (2013), página A 14, terça-feira, 23 de abril

O Estado de São Paulo, (2013-a), página A13, quinta-feira, 25 de abril de 2013.

Okhuysen, P.C., Chappell, C.H., Crabb, J.H., Sterling, C.R., DuPont, H.L. (1999), Virulence of 3 Cryptosporidium parvum isolated from health adults, J. Infec. Dis. $\mathrm{N}^{\circ} 180$, pp 1275 1281.

Petrovic, M., Farré, M., Lopez de Alda, M., Perez, S., Postigo, C., Köck, M., Radjenovic, J., Gros, M., Barcelo, D., (2010), Recent trends in liquid chromatography-mass spectrometry analysis of organic contaminants in environmental samples, Journal of Cromatography A, 1217, p.4004-4017 - analysis.

Rosenfeldt, E.J., and Linden, K.G., (2004), Degradation of endocrine disrupting chemicals-bisphenol A, etinil estradiol, and estradiol during UV Photolysis and advanced Oxidation processes, Environmental Science \& Technology, vol 38, no. 20, p.5476-5483.

Ryu, H., Alum, A. Mena, K.D., Abbaszadegan, M., (2007), Assessment of the risk of Cryptosporidium and Giardia in non-potable reclaimed water, Water Science \& Technology, vol. 55, ${ }^{\circ}$ 1-2, pp 283-290, IWA Publishing.

Shuval, H.I., at Al, (1986), Wastewater Irrigation in Developing Countries: Health effects and technical solutions. Washington, D.C., Banco Mundial.

Ternes, T.A., Stumpf. M., Mueller, J., Haberer, K., Wilken, R.D., e Servos, M., (1999), Behavior and occurrence of estrogens in municipal sewage treatment plants - I. Investigations in Germany. Canada and Brazil, The Science of the Total Environment 225, p.81-90, Elsevier Science, B.V.

WHO (1990), "Basic Documents", 38 ${ }^{\text {th }}$ Edition, World Health Organization, Geneva, Switzer- land.

WHO(1990a), "Guidelines for Drinking Water Quality", $3^{\text {rd }}$ Edition, World Health Organization, Geneva, Switzerland.

WHO, (2011), Guidelines for Drinking Water Quality, $4^{\text {th }}$ ed., p.541, Geneva, Switzerland.

WHO (1989), Health Guideflines for the Use of Wastewater in Agriculture and Aquaculture", Report of a WHO Scientific Group, Technical Report Series N167 778, World Health Organization, Geneva, Switzerland.

WHO, (2006), Guidelines for the Safe Use of Wastewater, Excreta and Greywater, Vol. II, Wastewater Use in Agriculture, p. 196, Geneva, Switzerland

\section{SOBRE O AUTOR}

\section{Ivanildo Hespanhol}

Engenheiro Civil, Engenheiro Sanitarista e Doutor em Saúde Pública pela Universidade de São Paulo, M.Sc. e Ph.D. em Engenharia pela Universidade da Califórnia em Berkeley, Professor Titular da Escola Politécnica da Universidade de São Paulo e Diretor do Centro Internacional de Referência em Reúso de Água-CIRRA/IRCWR/USP. Durante aproximadamente 10 anos (1987-1995) foi membro do Corpo Científico da Organização Mundial da Saúde, em Genebra, coordenando o programa Global Environmental Monitoring System-GEMS/WATER e colaborando na elaboração de diretrizes da OMS para água potável e reúso de esgoto e excreta na agricultura e na aquicultura. 